\title{
HOME CARE COM ASSISTÊNCIA DE ENFERMAGEM AO RECÉM-NASCIDO PRÉ-TERMO ICTÉRICO EM FOTOTERPIA: REVISÃO BIBLIOGRÁFICA
}

\author{
Samira Marques da Silva ${ }^{1}$ \\ Marcio Antonio de Assis 2
}

\begin{abstract}
RESUMO: O termo Home Care (HC) é originado do inglês, com um significado próximo à Assistência Domiciliar. Home Care pediátrico, é o atendimento domiciliar realizado por uma equipe multidisciplinar especializada, com médico, enfermeiro e equipe, psicólogos, entre outros. Os recém-nascidos pré-termo (RNPT) são acompanhados em HC para: ganho de peso, aleitamento materno, estimulação sensório-motora, icterícia sob fototerapia, dentre outros. OBJETIVO: Analisar na literatura nacional a assistência de enfermagem em domicilio em relação ao RNPT ictérico que necessita de fototerapia. MÉTODO: Revisão bibliográfica, realizada entre abril de 2019 a fevereiro de 2020. A busca foi realizada cruzando-se " assistência domiciliar" com os demais descritores. Das 8I publicações levantadas, 7I foram da SCIELO, e io da LILACS, sendo selecionados o7 artigos. Três publicações eletrônicas foram introduzidas, totalizando io publicações selecionadas. As demais foram excluídas, não completando os critérios de inclusão. RESULTADOS: Evidenciou-se a atuação do enfermeiro, inserido na equipe multidisciplinar do $\mathrm{HC}$, em cuidados ao $\mathrm{RN}$ ictérico em domicilio. Torna-se crucial diferenciar a icterícia fisiológica (surge após $48 \mathrm{~h}$ de vida) da icterícia patológica (surge antes das $24 \mathrm{~h}$ de vida), pois o uso exclusivo de fototerapia, geralmente auxilia no tratamento da icterícia fisiológica. Deve acompanhar os níveis de bilirrubina (direta e indireta) associando à idade gestacional ao nascer e a idade em horas de vida da criança. Durante o uso da fototerapia, prover a irradiância adequada e o correto posicionamento para uma maior abrangência da área corporal da criança, que permanecerá apenas com o uso da fralda para melhor eficiência do tratamento. Orientar familiares quanto a ação terapêutica dessas lâmpadas, ora fluorescentes (Biliberço) ou halógenas-azuis (Bilispot) minimizando os níveis de bilirrubina. Os genitores têm medo de superaquecimento e possíveis queimaduras no bebê, sem falar do uso desconfortável, porém necessário da proteção ocular da criança. O desconhecimento da terapêutica gera ansiedade aos pais ao ver o filho submetido a um tratamento para eles desconhecido. Cabe à enfermagem utilizar linguagem acessível durante as orientações. Deve-se estimular cuidados diretos ao filho, visto como um ser vulnerável às infecções, devido a prematuridade. Estimular o aleitamento materno, pelos seus atributos, sendo suspenso só por indicação médica.
\end{abstract}

\footnotetext{
I Bacharelado em Enfermagem da Universidade de Mogi das Cruzes. E-mail: samiradoors@hotmail.com>

${ }^{2}$ Pós - Doutorado em Enfermagem pela Universidade Estadual Paulista UNESP. Botucatu.

Docente da UMC. Enfermagem pelo Centro Universitário Nove de Julho UNINOVE.

Mestrado e Doutorado em Engenharia Biomédica pela Mogi das Cruzes UMC.
} 
CONCLUSÃO: Os cuidados de enfermagem em domicílio ao RN ictérico, sob fototerapia, com serviço HC, contribui para um novo olhar de assistência humanizada e de qualidade.

Descritores: Assistência Domiciliar. Enfermagem. Recém-Nascido Pré-Termo. Icterícia.

\section{INTRODUÇÃO}

Segundo Sarmento (2005), o termo Home Care é uma nomenclatura originada do inglês, e frequentemente empregada no Brasil com um significado próximo à Assistência Domiciliar. Registros marcam em 1949, no Rio de Janeiro, a primeira referência de assistência domiciliar no Brasil chamada de Assistência Médica Domiciliar e de Urgência (SAMDU).

Nessa linha histórica, em 1968, na cidade de São Paulo, segundo Malagutti (2012) o Hospital do Servidor Público Estadual implanta um serviço de estruturação no atendimento domiciliar, pensando em diminuir a permanência dos pacientes nesse referido hospital.

No fim da década de 1980 surge, em São Paulo, a primeira empresa privada de Home Health Care, ainda sem interesse em planos de saúde. A partir de 1995, as operadoras de plano de saúde descobrem o potencial da assistência domiciliar como forma de gestão em saúde (Sarmento, 2005).

Na década de 1990, Malagutti (2012) relata que o Ministério da Saúde cria o Programa de Saúde da Família (PSF), e a Universidade de São Paulo (USP) inaugura o Núcleo de Assistência Domiciliar Interdisciplinar (NADI).

No Sistema Único de Saúde (SUS) o Home Care está mais atuante na área de atendimento domiciliar, o que sugere mais estudos para crescimento na área da internação domiciliar, esse ainda mais voltado ao setor privado, podendo diminuir assim, o número de pacientes a espera de leitos e de pacientes crônicos sem os devidos cuidados. Nota-se que, há uma relação íntima entre a Assistência Domiciliar e Humanização no tratamento de qualquer que seja a doença. Um paciente, em sua residência, gera diminuição nas despesas com o tratamento, cuidados mais próximos de sua vida social, diminuição de processos infecciosos por estar em ambiente extra hospitalar, liberação de leitos hospitalares para atendimento de novos pacientes dentre outras vantagens (GARCIA, 20I4). 
Atualmente observa-se uma crescente significativa no Home Care em todo mundo, aparentemente sendo a grande descoberta gestacional e operacional da saúde mundial (GARCIA, 2014).

Segundo Troiano (2019), em julho de 2012 havia no Brasil, 18 empresas de Home Care, sendo que em julho de 2018 houve um incremento para 676 empresas desse atendimento domiciliar, havendo um aumento de $3.656 \%$ em número de empresas. Deve-se enfatizar que um serviço de assistência domiciliar, desde o mais simples até o mais complexo, só pode ser concebido a partir da existência da rede de unidades de saúde que oferece a retaguarda hospitalar e ambulatorial para os pacientes, sejam públicas ou privadas. Não confundir com familiares e amigos que prestam cuidados, auxiliando a pessoa em seu domicilio.

Segundo a literatura, há bem pouco tempo atrás era comum que crianças e recém-nascidos (RN) com doenças crônicas e necessidades especiais, vivessem em hospitais. Atualmente esse cenário é muito diferente. A tecnologia tem sido uma aliada na implantação de equipamentos e materiais que permitem a internação pediátrica domiciliar, com segurança equalidade. Os recursos tecnológicos permitiram sobretudo desospitalizações de alta complexidade e alto nível de cuidado. A desospitalização é uma estratégia eficaz, que humaniza o atendimento na saúde, racionaliza os leitos hospitalares, aumenta a qualidade de vida e o bem-estar da criança, e otimiza os custos dos planos de atenção (PEDILAR, 2019).

Nessa perspectiva, Home Care pediátrico, é um serviço de atendimento domiciliar realizado por uma equipe multidisciplinar especializada, que conta com médico pediatra, fisioterapeuta, enfermeiro, nutricionista, técnicos de enfermagem e fonoaudiólogo entre outros profissionais, conforme a demanda do paciente. A atenção domiciliar é indicada pelo profissional que atende a criança ou recém-nascido no hospital. Contudo, somente os casos de crianças com patologias agudas ou crônicas, que estão em condições de estabilidade podem receber a assistência em casa (PEDILAR, 2019)

Além de crianças com necessidades que demandam atenção e cuidados especiais do básico ao avançado e equipe multidisciplinar, os RN pré-termos (RNPT) também necessitam de acompanhamento. Cabe ressaltar que o RNPT ou prematuro é toda criança nascida antes 
de 37 semanas da idade gestacional (IG); o de termo (RNT) abrange de 37semanas até 42 sem. de IG e, o Pós Termo entre 42 sem. até 44 sem IG (LEONE et al, 2012)

RODRIGUES et al (20II), alegam que a Organização Mundial da Saúde, definiu o nascimento prematuro como o que ocorre após a $20^{\underline{a}}$ e antes $d a 37^{\underline{a}}$ semana de gestação. A prematuridade pode ser classificada em três categorias: leve, quando ocorre entre 32 e 36 semanas de gestação, moderada ( 28 e 3 I semanas) e severa (abaixo de 28 semanas).

Apesar dos avanços tecnológicos estarem provendo melhores condições de atendimento e sobrevida das crianças que nascem prematuramente, em proporções mundiais, um a cada dez nascimentos foi prematuro no ano de 2010, sendo estimados quinze milhões de nascimentos. Isso representa uma taxa de II,I\% dos nascimentos, com um milhão de óbitos em decorrência direta do nascimento prematuro (OLIVEIRA et al, 2016).

Devido a uma grande taxa de mortalidade infantil no período lactente, os profissionais procuram implementar assistência técnico-científica cada vez mais qualificada. É importante enfatizar o papel da enfermagem humanizada aos pais dessas crianças, respeitando suas crenças e valores. (GUIMARÃES et al, 2017).

BRASIL (2013) salienta a importância da assistência domiciliar materno-infantil, por meio da Rede Cegonha, onde o cuidado é direcionado em especial a neonatos com indicação de fototerapia, prematuros e/ou de muito baixo peso, que necessitem de antibioticoterapia venosa e de terapia respiratória não invasiva, além de cuidados a lactentes com déficit neurológico, traqueostomizados ou gastrostomizados. Para a mãe, as indicações referemse a complicações do parto, tais como a infecção puerperal, as complicações de pós- operatório entre outras.

Nessa ótica da assistência humanizada deve-se estabelecer estratégias realizando uma ligação direta entre a família, o RN e o profissional, tendo como cuidado um processo longo que demanda tempo e experiência para que seja eficaz. Esse processo exige dos profissionais comprometimento, responsabilidades, habilidades técnico-cientificas, acrescido de apoio emocional à família (FERREIRA, 1998).

A Resolução do Conselho Federal de Enfermagem (COFEN) no 0464/ 2014 considera atenção domiciliar de enfermagem as ações desenvolvidas no domicílio da pessoa, que visem à promoção de sua saúde, à prevenção de agravos e tratamento de doenças, bem 
como à sua reabilitação e nos cuidados paliativos. Em seu Art. $3^{\circ}$ determina que a atenção domiciliar de enfermagem deve ser executada no contexto da Sistematização da Assistência de Enfermagem, sendo pautada por normas, rotinas, protocolos validados e frequentemente revisados, com a operacionalização do Processo de Enfermagem, de acordo com as etapas previstas na Resolução COFEN no 358/2009, a saber: I. Coleta de dados (Histórico de Enfermagem); II. Diagnóstico de Enfermagem; III. Planejamento de Enfermagem; IV. Implementação; e V. Avaliação de Enfermagem. Em seu Art. $4^{o}$ salienta que todas as ações concernentes à atenção domiciliar de enfermagem devem ser registradas em prontuário, a ser mantido no domicílio, para orientação da equipe, dentre essas os resultados alcançados como consequência das ações ou intervenções de enfermagem realizadas (COFEN, 2014).

Conhecendo o potencial para aquisição de afecções do RNPT diante de suas características anátomo-fisiológicas e sistema imunológico imaturos, acrescido ao medo e insegurança dos genitores por tais fragilidades apresentadas pelo filho, principalmente durante a hospitalização, o referido estudo tem como objeto evidenciar a importância do tratamento do RNPT ictérico, em condições clínicas estáveis, necessitando do uso de fototerapia em atendimento domiciliar e assistência de enfermagem, inserida no contexto interdisciplinar. Deve-se enfatizar, que a icterícia ou hiperbilirrubinemia do RN pode ser fisiológica ou patológica que acomete com frequência tanto o RNPT, como o RNT. As manifestações clínicas são caracterizadas pela coloração amarelada da pele, mucosas e escleróticas decorrente da elevação de bilirrubina no sangue. A bilirrubina é formada principalmente pelo catabolismo da hemoglobina e, os principais locais de formação são o baço e o fígado. Aproximadamente $75 \%$ da bilirrubina é derivada do catabolismo de glóbulos vermelhos, $25 \%$ da eritropoiese ineficiente, do catabolismo das hemoglobinas e heme livres do fígado. Um grama de hemoglobina catabolizada resulta na produção de $35 \mathrm{mg}$ de bilirrubina. Um recém-nascido a termo (RNT) saudável produz, em média, 2,3 mg de bilirrubina $/ \mathrm{kg} / \mathrm{dia}$. A icterícia patológica envolve a toxicidade da bilirrubina no sistema nervoso central gerando agravos e podendo levar à morbimortalidade ao RN. O termo Kernicterus é reservado à forma crônica da doença, com sequelas clínicas permanentes resultantes da toxicidade da bilirrubina no sistema nervoso central. A fototerapia geralmente é o tratamento inicial da icterícia, podendo em casos mais críticos, ser concomitante com a exsanguineotransfusão e 
terapia farmacológica, sendo as duas últimas modalidades geralmente realizadas durante a hospitalização (TAMEZ; SILVA, 20ı0).

Nesse contexto, Munhoz et al (2018) evidenciam o metabolismo da bilirrubina que se liga à albumina no plasma, visto que é insolúvel neste meio. A bilirrubina não conjugada ou indireta (BI) é a bilirrubina ligada à albumina. No hepatócito ocorre a captação da BI, a conjugação, isto é, a BI sofre transformação pela enzima glucoronil-transferase na bilirrubina direta (BD) ou conjugada, tornando-se polar e hidrossolúvel e capaz de ser excretada através da bile. A bile, ao ser excretada no lúmen intestinal, é metabolizada por bactérias e forma-se o urobilinogênio que é reabsorvido e excretado na urina e o restante é excretado nas fezes. $\mathrm{O}$ valor normal da bilirrubina total é de o,2 a 1,o mg/dL. A bilirrubina conjugada 0,1 a $0,3 \mathrm{mg} / \mathrm{dL}$ e a bilirrubina não-conjugada 0,2 a $0,8 \mathrm{mg} / \mathrm{dL}$. A icterícia é detectável quando os níveis são maiores que 2,5 a $3 \mathrm{mg} / \mathrm{dL}$. A hiperbilirrubinemia e a icterícia podem ocorrer através do aumento da produção de bilirrubina ou através da diminuição da depuração da bilirrubina. A hiperbilirrubinemia não-conjugada (BI) ocorre por aumento da produção, captação e conjugação prejudicadas da bilirrubina e a hiperbilirrubinemia conjugada (BD) é decorrente de lesões hepatocelulares ou por obstrução intra ou extra-hepáticas.

QUINTAL (1994) associa os índices de bilirrubina indireta (BI) e o peso dos RN mostrando a necessidade da introdução ou indicação da fototerapia, qual seja:

Pretendendo-se auxiliar na redução dos índices de morbimortalidade neonatal, em particular no tratamento do RNPT ictérico incentivando-se o uso de fototerapia em Home Care, buscando oferecer maior segurança aos pais nos cuidados diretos ao filho, estimulando o vínculo afetivo, esse estudo apresenta a seguinte questão: "Quais são as ações assistenciais de enfermagem em relação ao RNPT ictérico em uso de fototerapia em domicílio, no contexto familiar?

Esse estudo justifica-se por poder contribuir na melhoria da qualidade assistencial de Enfermagem, em se tratando da promoção, prevenção e reabilitação da saúde do RNPT que necessita de cuidados domiciliares em geral e, em particular nesse estudo, da assistência ao RNPT ictérico que faz uso de fototerapia domiciliar, no contexto familiar. 


\section{OBJETIVOS}

\section{GERAL}

Analisar na literatura cientifica nacional ações assistenciais de enfermagem em domicilio em relação ao RNPT que necessita de fototerapia no contexto familiar.

\section{ESPECIFICOS}

- Descrever principais cuidados ao RNPT em fototerapia domiciliar

- Evidenciar orientações com relação ao aleitamento materno à mãe do RNPT em uso de fototerapia domiciliar

- Levantar percepções e sentimentos da família em relação aos cuidados do RNPT em âmbito domiciliar

\section{MATERIAL E MÉTODO}

Trata-se de uma revisão bibliográfica, que caracteriza-se pela identificação e análise dos dados escritos em livros, artigos de revistas, dentre outras fontes de busca. Sua finalidade é colocar o investigador em contato com o que já se produziu a respeito do seu tema de pesquisa, estabelecendo melhor aprofundamento de dados especializados em cada área do saber. A pesquisa bibliográfica envolve as seguintes etapas: (I) escolha do tema; (2) levantamento bibliográfico preliminar; (3) formulação do problema; (4) elaboração do plano provisório do assunto; (5) busca das fontes; (6) leitura do material: exploratória, seletiva, analítica, interpretativa; (7) fichamento; (8) organização lógica do assunto; (9) redação do texto. (GIL, 2002).

Foram levantados estudos da base de dados da Scientific eletronic library on line (SCIELO), e estudos da Literatura Latino Americana e do Caribe em Ciências da Saúde (LILACS) por apresentarem expressivo acervo na temática. Como critérios de inclusão foram considerados publicações, dos últimos dez anos, em português, direcionadas à temática sobre principais ações assistenciais em relação aos RNPT que necessitam de cuidados domiciliares.

Foram excluídas publicações que não contemplaram os critérios de inclusão, com idiomas estrangeiros e acima de dez anos de publicação.

Para obtenção dos artigos foram utilizados os descritores ou palavras-chave em português: assistência domiciliar, enfermagem, recém-nascido pré-termo, ictericia validados pelos Descritores de Ciências da Saúde (DECs). Para a busca de títulos e resumos afins, foi 
selecionado o descritor principal "recém-nascido pré-termo" sendo cruzado com cada um dos demais descritores do estudo. O levantamento bibliográfico ocorreu entre os meses de abril de 2019 a fevereiro de 2020. Os artigos selecionados foram analisados e categorizados por meio de "Quadros" contendo: nome dos autores, título do estudo, objetivos e respectivos achados. Em seguida, interpretação e análise dos mesmos na discussão.

Foram elaboradas duas categorias, apresentadas por meio de dois Quadros, com as respectivas temáticas: Quadro I. Estudos sobre ações assistenciais de enfermagem em relação ao RNPT ictérico que necessita de fototerapia em âmbito domiciliar; Quadro 2. Estudos sobre ações assistenciais de enfermagem em relação à família do RNPT ictérico em âmbito domiciliar.

As publicações selecionadas seguiram a análise de conteúdo Bardin (2004), sendo realizado uma criteriosa leitura do material, com a codificação e agrupamento de informações sobre principais cuidados aos RNPT ictéricos, com atendimento domiciliar. Esse estudo não utilizou Termo de Compromisso Livre e Esclarecido por realizar revisão bibliográfica, não envolvendo seres humanos, respeitando-se os preceitos legais do Conselho Nacional de Saúde (CNS), com Resolução no 466, de i2 de dezembro de 2012. O estudo foi custeado pelo próprio pesquisador.

Das 8I publicações levantadas, 7I foram da SCIELO, e io da LILACS, sendo selecionados o7 artigos, constituídos por o6 da SCIELO e or da LILACS. Três publicações eletrônicas, ou seja, o2 Sites de teor educativo-científico, e or Reportagem realizada em Contagem, Minas Gerais, apesar de não inclusas nas bases pesquisadas, foram introduzidas, pela relevância no referido trabalho, totalizando io publicações selecionadas para os resultados.

Foram excluídos ıo por serem em idiomas estrangeiros; o6 acima de dez anos de publicação e 58 que não contemplaram os critérios de inclusão, por não serem objetos do referido estudo, envolvendo artigos de assistência domiciliar a idosos e capacitação da Enfermagem para assistência domiciliar. .

\section{RESULTADOS}

Após criteriosa leitura, foram destacados io estudos para o referido trabalho, contemplando os critérios de inclusão, sendo apresentados em Quadros, quais sejam: Quadro I: Estudos sobre ações assistenciais de enfermagem em relação ao RNPT ictérico que necessita de fototerapia, em âmbito domiciliar e Quadro 2: Estudos sobre 
ações assistenciais de enfermagem em relação à família do RNPT ictérico em âmbito domiciliar.

QUADRO I. ESTUDOS SOBRE AÇÕES ASSISTENCIAIS DE ENFERMAGEM EM RELAÇÃO AO RNPT ICTÉRICO QUE NECESSITA DE FOTOTERAPIA EM ÂMBITO DOMICILIAR.

\begin{tabular}{|c|c|c|c|}
\hline AUTOR/RES/ANO & TITULO & OBJETIVOS & ACHADOS \\
\hline $\begin{array}{l}\text { CASTRO, E et al } \\
(2011)\end{array}$ & $\begin{array}{l}\text { Atendimento de } \\
\text { Enfermagem } \\
\text { domiciliar na icterícia } \\
\text { neonatal }\end{array}$ & $\begin{array}{l}\text { Descrever conceito } \\
\text { sobre icteríci } \\
\text { neonatal e o } \\
\text { principais cuidado } \\
\text { de Enfermagem a } \\
\text { RN sob fototerapi } \\
\text { em domicílio po } \\
\text { meio da publicaçã } \\
\text { de Site educativo, d } \\
\text { teor científico. }\end{array}$ & 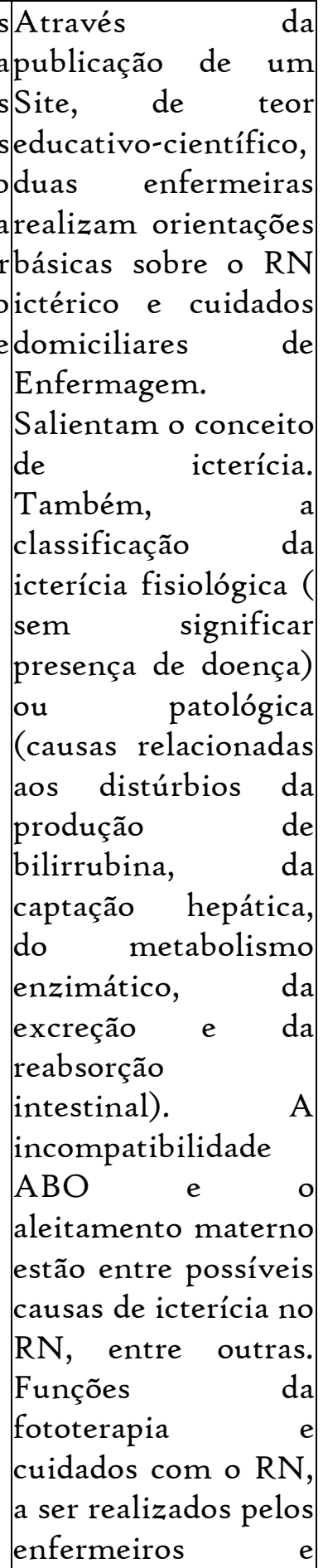 \\
\hline
\end{tabular}




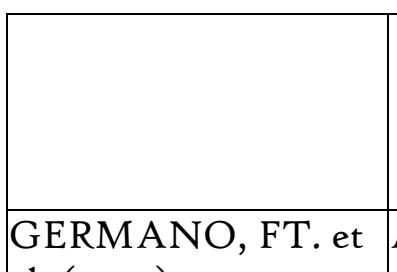
al. ( 2014)
Assistência de enfermagem ao recém-nascido em fototerapia: uma revisão de literatura

\section{Evidenciar} conhecimentos técnicos e científicosimportância acerca da assistêncialassistência de enfermagem a RN enfermagem para a com eficácia da

hiperbilirrubinemia

Revisão de literatura abordando a

equipe.

Interdisciplinar médico, psicólogo entre outros)

\section{fototerapia}

tratamento

hipebilirrubinemias

neonatais. Pode-se

perceber que a fototerapia é um tratamento que utiliza a energia luminosa para transformar

bilirrubina

acumulada

sangue em produtos mais hidrossolúveis, para serem

excretados

rapidamente pela bile e pela urina. A eficiência $\mathrm{da}$ terapêutica depende de alguns fatores,tais como: o nível sérico inicial bilirrubina, idade gestacional, irradiância do foco luminoso, o tipo de nutrição que o RN está recebendo, a superfície corporal que está exposta à luz, distância entre a fonte luminosa e o $\mathrm{RN}$, a idade de pós natal do RN com doenças associadas, proteína séricas, $\mathrm{pH}$, peso ao nascimento e a causa da icterícia. 


\begin{tabular}{|c|c|c|}
\hline $\begin{array}{|lr|}\text { BRASIL } & \text { (a) } \\
\text { Ministério da } & \text { Saúde, } \\
\text { Secretaria } & \text { de } \\
\text { Atenção à Saúde } & \text { do } \\
\text { Recém-nascido, } & \\
\text { Departamento r de } \\
\text { Ações Programáticas } \\
\text { e Estratégicas, (2014) }\end{array}$ & $\begin{array}{l}\text { Ações Programáticas } \\
\text { er Estratégias: } \\
\text { Intervenções comuns, } \\
\text { icterícia e infecções }\end{array}$ & 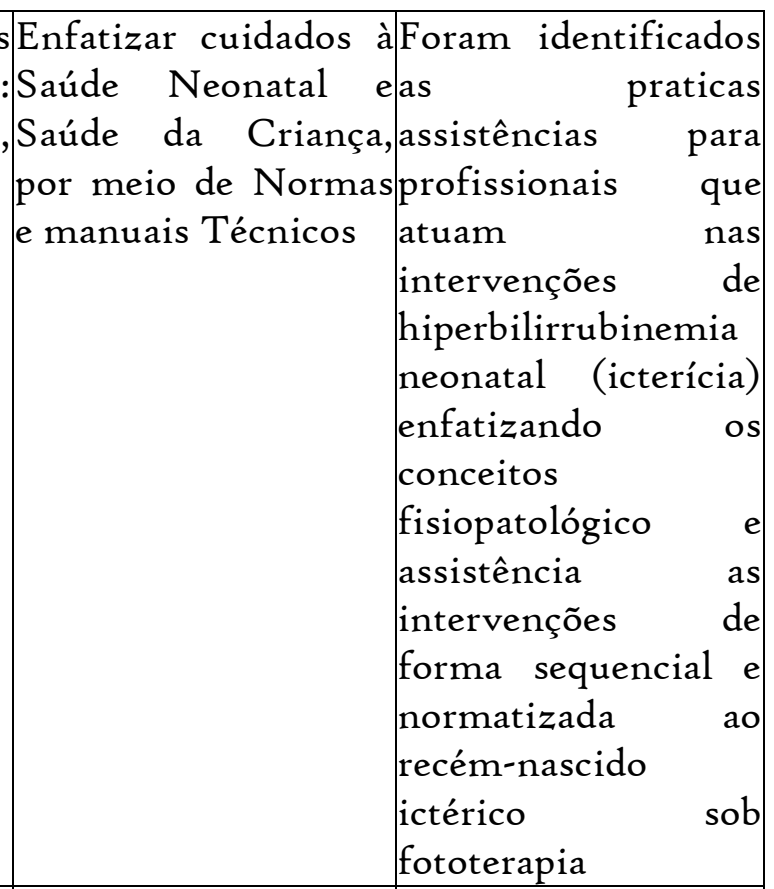 \\
\hline $\begin{array}{l}\text { PRADO FILHO, } \\
\text { HR ( 2019) }\end{array}$ & $\begin{array}{lr}\text { O desempenho } & \text { dos } \\
\text { equipamentos } & \text { de } \\
\text { fototerapia } & \text { para } \\
\text { recém-nascidos } & \\
& \end{array}$ & 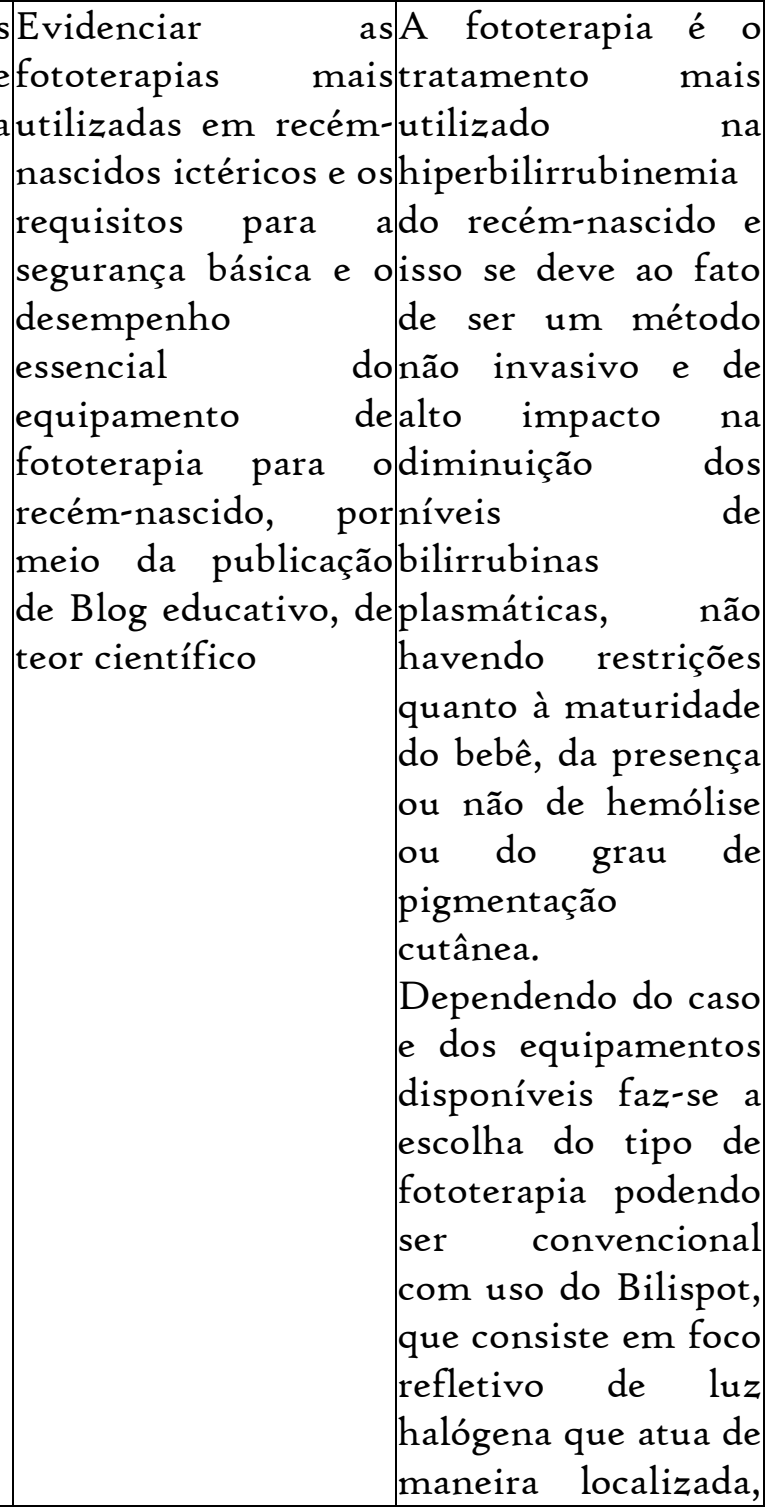 \\
\hline
\end{tabular}




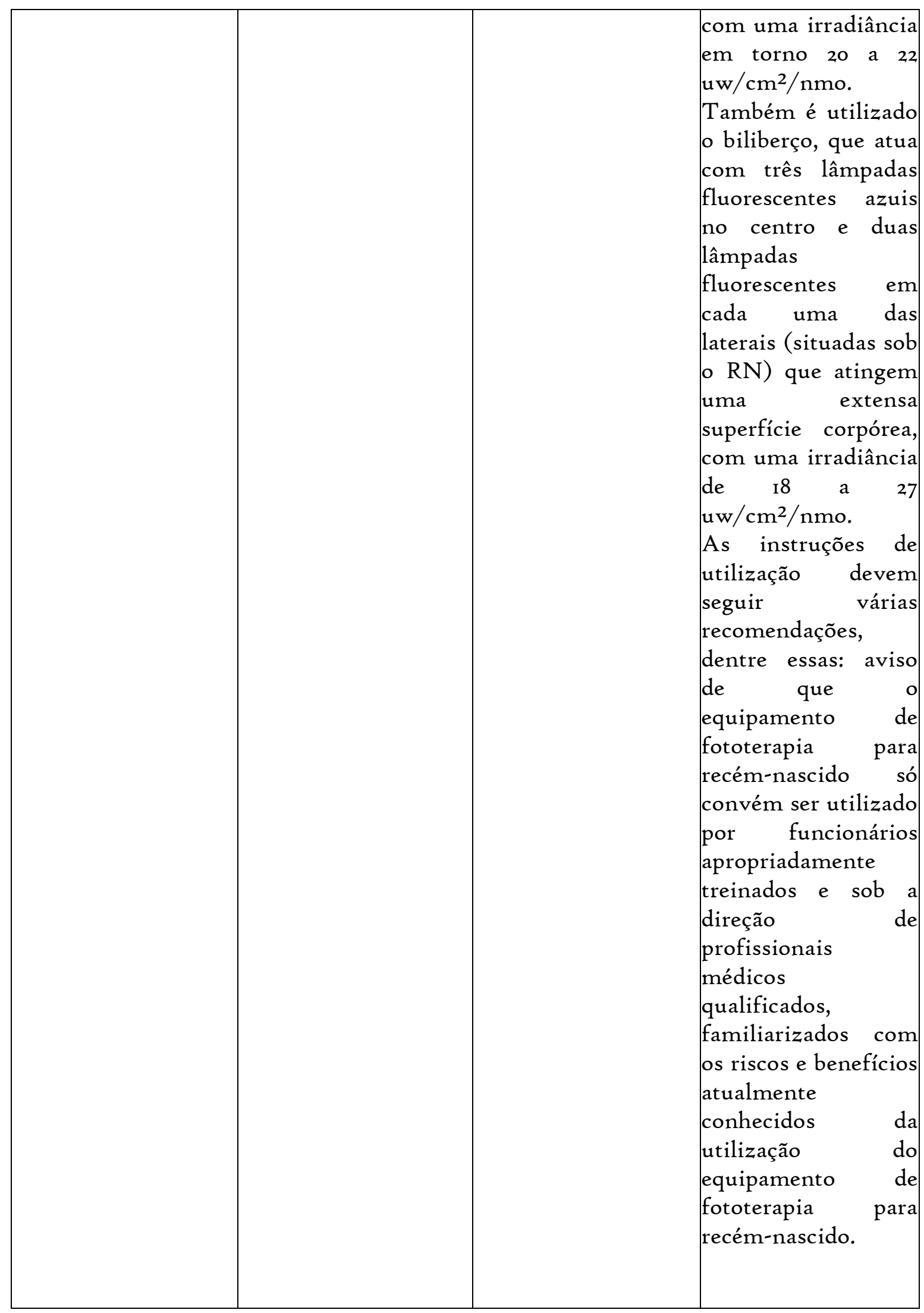

Fonte: Do autor (2020) 
QUADRO 2. ESTUDOS SOBRE AÇÕES ASSISTENCIAIS DE ENFERMAGEM EM RELAÇÃO À FAMÍLIA DO RNPT ICTÉRICO EM ÂMBITO DOMICILIAR.

\begin{tabular}{|c|c|c|c|}
\hline AUTOR/RES/ANO & TITULO & OBJETIVOS & ACHADOS \\
\hline $\begin{array}{l}\text { BOTELHO, SM et } \\
\text { al ( 2012) }\end{array}$ & $\begin{array}{lr}\text { O cuidar materno } \\
\text { diante do filho } \\
\text { prematuro: } & \text { ums } \\
\text { estudo } & \text { das } \\
\text { representações } & \\
\text { sociais } & \end{array}$ & $\begin{array}{l}\text { Apreender } \\
\text { representações } \\
\text { sociais de mães } \\
\text { sobre o cuidar } \\
\text { materno diante do } \\
\text { filho prematuro }\end{array}$ & $\begin{array}{l}\text { Teste de Associação } \\
\text { Livre de Palavras, } \\
\text { solicitou a } 30 \text { mães } \\
\text { participantes que } \\
\text { evocassem cinco } \\
\text { palavras sobre o cuidar } \\
\text { materno diante do } \\
\text { filho prematuro, } \\
\text { atribuindo ordem de } \\
\text { importância para as } \\
\text { palavras. } \\
\text { resultados apareceram } \\
\text { as palavras amor e } \\
\text { cuidado; angústia, } \\
\text { atenção, carinho, } \\
\text { paciência; } \\
\text { prevenção; } \\
\text { dedicação, alegria, } \\
\text { dependência, } \\
\text { dificuldade, } \\
\text { experiência, proteção, } \\
\text { responsabilidade, } \\
\text { superação. O amor e o } \\
\text { cuidado aparecem } \\
\text { como núcleo central } \\
\text { das representações. O } \\
\text { amor diz respeito ao } \\
\text { papel de mãe a ser } \\
\text { exercido. O cuidado } \\
\text { pode representar o } \\
\text { anseio de encontrar } \\
\text { melhorias para seu } \\
\text { filho }\end{array}$ \\
\hline $\begin{array}{l}\text { SASSÁ, AH. et al. ( } \\
\text { 20I4) }\end{array}$ & $\begin{array}{ll}\text { Ações } & \text { de } \\
\text { Enfermagem } & \text { na } \\
\text { assistência } & \\
\text { domiciliar ao Recém- }\end{array}$ & $\begin{array}{l}\text { Descrever as ações } \\
\text { de Enfermagem } \\
\text { implementadas no } \\
\text { contexto domiciliar, }\end{array}$ & $\begin{array}{l}\text { Pesquisa convergente- } \\
\text { assistencial realizada } \\
\text { com nove famílias, por } \\
\text { meio de visitas }\end{array}$ \\
\hline
\end{tabular}




\begin{tabular}{|c|c|c|c|}
\hline & 1655 & $\mid \begin{array}{l}\text { Nascido de muito } \\
\text { baixo peso }\end{array}$ & 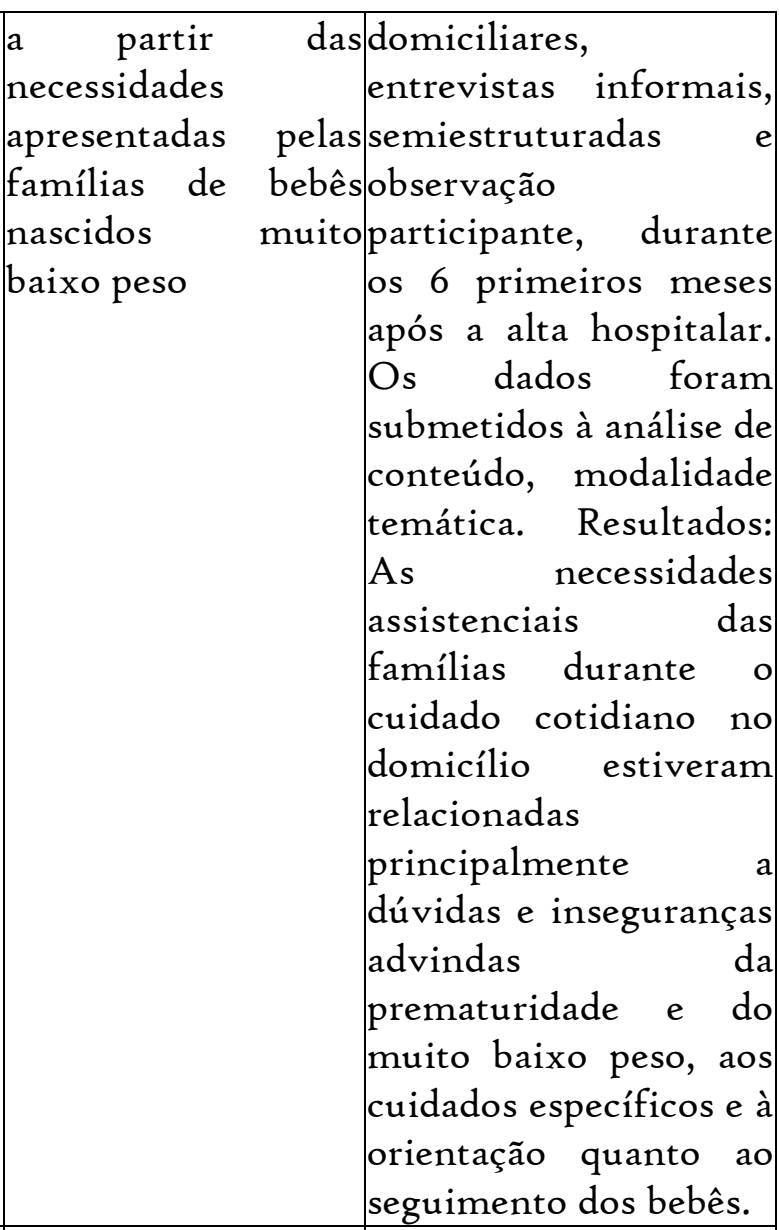 \\
\hline & BRAUER, C ( 2017) & $\begin{array}{l}\text { Primeiro } \\
\text { atendimento de } \\
\text { fototerapia feito em } \\
\text { casa: Reportagem }\end{array}$ & 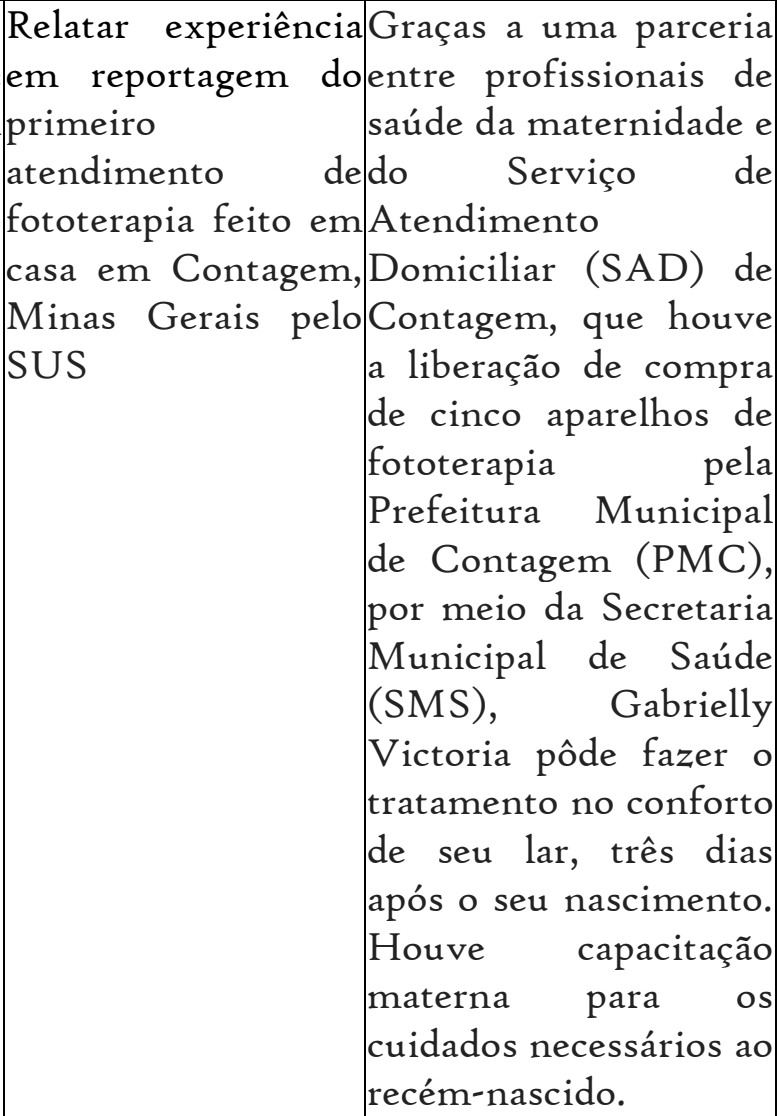 \\
\hline
\end{tabular}




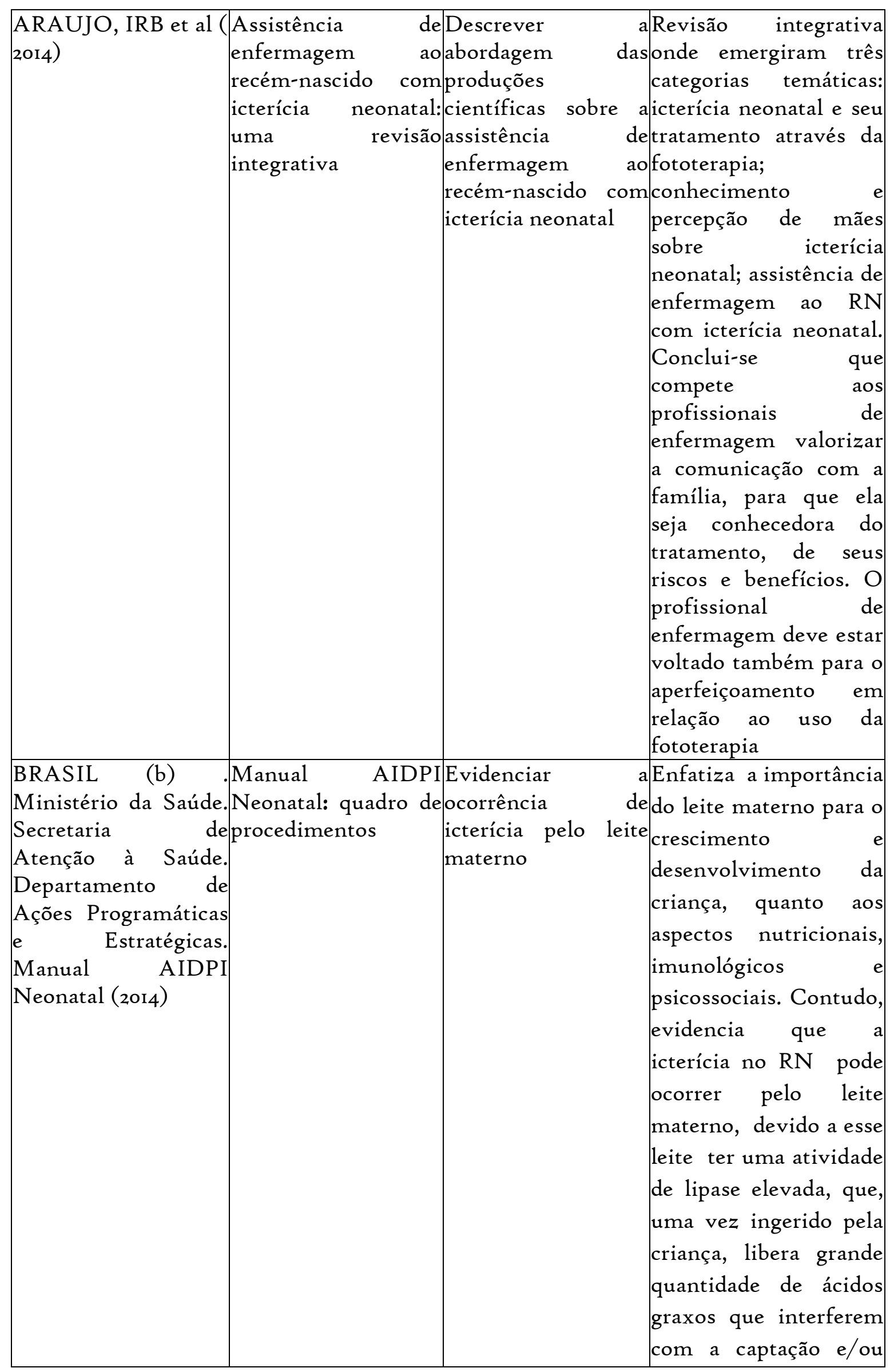




\begin{tabular}{|c|c|c|c|}
\hline & & & 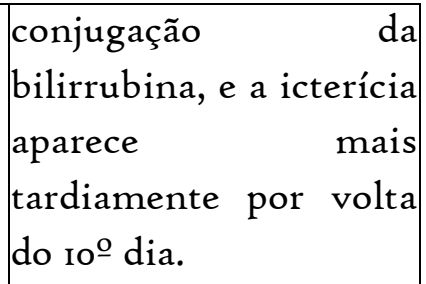 \\
\hline DALCIN, T ( 2016) & $\begin{array}{l}\text { Como identificar e } \\
\text { manejar a icterícia } \\
\text { do leite materno? }\end{array}$ & $\begin{array}{l}\text { Identificar } \\
\text { manejar a icterícia } \\
\text { do leite materno }\end{array}$ & $\begin{array}{l}\text { Aconselha-se a não } \\
\text { orientar a suspensão do } \\
\text { leite materno ou } \\
\text { amamentação } \\
\text { rotineiramente, mesmo } \\
\text { confirmado a icterícia } \\
\text { proveniente desse leite } \\
\text { materno, a não ser se } \\
\text { os níveis totais de } \\
\text { bilirrubina estiverem } \\
\text { próximos aos níveis de } \\
\text { indicação } \\
\text { exsanguíneotransfusão, } \\
\text { com acompanhamento } \\
\text { médico. }\end{array}$ \\
\hline
\end{tabular}

Fonte: Do autor (2020)

\section{DISCUSSÃO}

Em relação ao Quadro I: "Estudos sobre ações assistenciais de enfermagem em domicilio em relação ao RNPT ictérico que necessita de fototerapia”, CASTRO et al (20II) enfermeiras em atendimento domiciliar aos RN, na elaboração de um blog educativo, de teor científico, direcionado aos acadêmicos e profissionais de Enfermagem, enfatizam os principais conceitos sobre icterícia e cuidados de Enfermagem ao neonato sob fototerapia, mostrando como esse atendimento pode ser realizado em casa. Salientam que a icterícia é a coloração amarelada da pele causada pelo aumento da bilirrubina, que pode ou não indicar estado patológico, com evolução crânio-caudal. A icterícia fisiológica ou tardia surge após 48 horas de vida com autolimitada, sem significar presença de doença. Todavia, se o $\mathrm{RN}$ for prematuro, existe a necessidade da fototerapia para evitar a impregnação da bilirrubina no cérebro. A icterícia patológica ou precoce, surge antes das 24 horas de vida, tendo como causas principais: a doença hemolítica, infecções congênitas e sepse. Cabe ressaltar, que devido a imaturidade hepática do $\mathrm{RN}$, as fases de captação e conjugação da bilirrubina indireta são comprometidas, aumentando a circulação da mesma no sangue, podendo levar à encefalopatia bilirrubínica ou Kernicterus, com comprometimento do 
sistema nervoso central. A doença hemolítica, é grave, sendo tratada em ambiente hospitalar e, acomete o feto e o RN sendo causada pelos anticorpos maternos (IgG), devido a sensibilização anterior, durante o parto, amniocentese traumática, heterotrnasfusões, Incompatibilidade $\mathrm{Rh}$, incompatibilidade ABO. A exsanguíneotransfusão é utilizada para corrigir a anemia, remover anticorpos, diminuir a bilirrubina, sendo indicada quando a fototerapia sozinha não resolve. Nesse caso, o sangue do $\mathrm{RN}$ é retirado, em geral 5 a Ioml de cada vez e substituído com sangue compatível $\mathrm{Rh}$ negativo, sendo geralmente realizado em ambiente hospitalar. As autoras relatam que as principais causas da icterícia fisiológica são: aleitamento materno, incompatibilidade $\mathrm{ABO}$, distúrbios metabólicos, uso de drogas, estados como a sífilis congênita, predisposição genética. Para o diagnóstico deve-se avaliar: História materna (Anamnese), Exame físico do RN (Zona de Kramer, anemia), Tipagem sanguínea e fator Rh da mãe e do RN, Hemograma, Bilirrubina total e frações, Coombs indireto da mãe (positivo), Coombs direto do RN (positivo), e RN Rh+ e mãe Rh - (negativo). O Kernicterus ou Encefalopatia bilirrubínica é a principal complicação, podendo deixar sequelas clínicas permanentes devido a toxicidade bilirrubinica, com retardo mental, alterações no desenvolvimento motor (ataxia), distúrbios comportamentais e perda da audição neurossensorial.

Quanto ao tratamento domiciliar utiliza-se a fototerapia para prevenir a encefalopatia bilirrubinica. A fototerapia se dá pela aplicação de luz à pele exposta da criança. Seu mecanismo ocorre pela transformação (fotoxidação e isomerização) da bilirrubina indireta (BI), molécula lipossolúvel em uma molécula mais hidrossolúvel, a bilirrubina direta (BD) assim sendo mais facilmente eliminada do organismo. Como efeitos colaterais pode-se detectar: fezes amolecidas, rubor, bronzeamento da pele, hipertermia, queimaduras, erupções cutâneas. As cinco zonas de Kramer, de progressão céfalo-caudal da icterícia são: As autoras Castro et al (20II) ainda enfatizam os principais cuidados do RN em fototerapia, sendo: - Manter RN despido, proteger genitais; -Proteger os olhos com vendas apropriadas (protetor ocular), as pálpebras devem estar fechadas; -Posicionar o foco de luz de modo a atingir uma maior área corporal;- Manter uma distância de 5ocm das lâmpadas do aparelho; - Mudar decúbito a cada 4 horas; Fazer balanço hídrico rigoroso; - Verificar intensidade da luz; -Amamentação por livre demanda; -Controle do tempo de permanência da lâmpada fluorescente ligada, com anotação de data e número de horas/dia(o tempo de vida útil da lâmpada); - Controle rigoroso da temperatura corporal, pois pode ocorrer um hiperaquecimento pela ação do calor da lâmpada - 4/4horas; - Controle do estado de 
hidratação do RN, pois pode ocorrer desidratação devido á sudorese pela ação do calor; Limpeza frequente do berço e do RN; - Retirada do RN da fototerapia para a amamentação, mesmo que a prescrição seja contínua; - Fototerapia pode ser intermitente ou contínua de acordo com a prescrição médica; -Avaliar os olhos em busca de secreção ou pressão excessiva sobre as pálpebras; - Desligar o aparelho de foto ao colher sangue para exame; - Remover a venda por ocasião das mamadas e banho; - Retirada do RN da fototerapia, 15 minutos antes do banho, para que seu corpo não sinta a diferença de temperatura.

Sendo assim, o adequado planejamento assistencial de enfermagem, associado a orientações e esclarecimento de dúvidas da família sobre o tratamento, torna-se fundamental para a intervenção efetiva ao RN em fototerapia no domicilio.

GERMANO et al (2014) abordam a assistência de enfermagem ao RN em fototerapia, evidenciando o conhecimento do enfermeiro para diversos aspectos, que vão desse o cuidado com a pele do RN, a fisiopatologia da icterícia, incluindo os cuidados com os adequados equipamentos utilizados como os vários tipos de fototerapia. O comprimento de luz efetivo para absorção da bilirrubina encontra se na faixa de 400-500 $\mathrm{nm}$. A luz emitida nessa faixa penetra na epiderme atingindo o tecido subcutâneo. Assim, apenas a bilirrubina que está próxima à superfície da pele (até $2 \mathrm{~mm}$ ) será afetada diretamente. Então, como a fototerapia age no nível da pele do RN, infere-se que a superfície corporal exposta à luz é um importante determinante da sua eficácia. Dessa forma, quanto maior a área irradiada, maior a eficácia da terapia. Por isso, deve- se evitar o uso de fraldas em RN ictéricos, uma vez que as áreas da pele cobertas durante o tratamento, permanecem visivelmente ictéricas reduzindo a efetividade da terapia fototerápica. Entretanto, a utilização de materiais na fototerapia pode aumentar o risco de sobreaquecimento, além de diminuir a visibilidade do profissional em relação ao neonato A eficácia da fototerapia diminui à medida que a concentração sérica de bilirrubina cai. Sua eficácia é mínima com concentração sérica igual ou inferior a $5 \mathrm{mg} \%$. A instalação da fototerapia e os cuidados com o neonato fazem parte da rotina da assistência prestada pela equipe de enfermagem no ambiente hospitalar. Tal abordagem dos autores citados anteriormente, mostram a importância do enfermeiro estar qualificado para poder atuar na assistência ao RN que fará uso de fototerapia em domicilio.

BRASIL (2014a), apresenta Normas e Manuais Técnicos do Ministério da Saúde que enfatizam cuidados à Saúde Neonatal e à Saúde da Criança, incluindo cuidados que devem 
ser seguidos durante o uso de fototerapia, quais sejam: - Verificar a temperatura corporal a cada três horas para detectar hipotermia ou hipertermia, e o peso diariamente; Aumentar a oferta hídrica, pois a fototerapia com lâmpada fluorescente ou halógena pode provocar elevação da temperatura, com consequente aumento do consumo de oxigênio, da frequência respiratória e do fluxo sanguíneo na pele, culminando em maior perda insensível de água; Proteger os olhos com cobertura radiopaca por meio de camadas de veludo negro ou papel carbono negro envolto em gaze; Não utilizar ou suspender a fototerapia se os níveis de bilirrubina direta estiverem elevados ou se houver colestase, para evitar o aparecimento da síndrome do bebê bronzeado, que se caracteriza pelo depósito de derivados de cobreporfirina no plasma, urina e pele; Em caso do uso de solução parenteral (internação domiciliar) cobrir o equipo com papel alumínio ou usar extensores impermeáveis à luz, pois a exposição de soluções de aminoácidos ou multivitamínicas ao comprimento de luz azul reduz a quantidade de triptofano, metionina e histidina. Adicionalmente, a solução de lipídeos é altamente susceptível à oxidação quando exposta à luz, originando hidroperóxidos de triglicérides citotóxicos; Prover a prática da descontinuidade da fototerapia durante a alimentação, inclusive com a retirada da cobertura dos olhos, desde que a bilirrubinemia não esteja muito elevada. Sendo assim, cabe à Enfermagem a implementação dessas ações assistenciais entre outras, acrescido às orientações e retirada de dúvidas dos familiares, minimizando a ansiedade dos genitores.

PRADO FILHO (2019) evidencia o desempenho das fototerapias que são utilizadas no RN ictérico. O autor apresenta a NBR IEC 6060I-2-50 de 08/2019 - Equipamento eletromédico - Parte 2-50 que determina requisitos particulares para a segurança básica e o desempenho essencial do equipamento de fototerapia para o recém-nascido. $O$ fabricante deve informar o efeito da variação das condições ambientais sobre o paciente, como, por exemplo, a variação da temperatura ambiente, fontes de radiação diferentes (luz solar). Também, um aviso com informações sobre o filtro e a barreira de proteção prescritos para a utilização normal; outro aviso de que o equilíbrio hídrico de alguns pacientes pode ser afetado e, que pacientes próximos ao equipamento de fototerapia para recém-nascido podem precisar de proteção, Outrossim, explicar sobre as medidas de proteção adicionais por exemplo, anteparos, óculos de proteção para o $\mathrm{RN}$; enfatizar que os valores de bilirrubina do paciente devem ser medidos regularmente. Também, de que a utilização de lâminas refletoras pode gerar temperaturas corporais perigosas, se isto for relevante para o tipo de 
equipamento de fototerapia para recém-nascido e, reforçar de que a luz azul pode atrapalhar as observações clínicas porque pode mascarar mudanças na cor da pele, como cianose. Importante ter um aviso, caso não seja permitida a aplicação de soluções inflamáveis (antissépticos, agentes de limpeza etc.), no equipamento de fototerapia para recém-nascido; um aviso que, devido aos efeitos da luz, drogas e líquidos de infusão não podem ser armazenados na área de radiação; informações avisando o operador sobre quaisquer riscos associados à operação do equipamento de fototerapia para recém-nascido na presença de gases que podem manter a combustão (por exemplo, oxigênio, óxido nitroso, agentes anestésicos) e como utilizar apropriadamente o equipamento de fototerapia para recém-nascido na presença destes gases. O equipamento em deve ser projetado de forma que a interrupção e a restauração do fornecimento de energia elétrica com paradas de até io min interrompam o tratamento e o operador seja informado ou os valores pré-ajustados não sejam alterados.

Dependendo do caso e dos equipamentos disponíveis faz-se a escolha do tipo de fototerapia podendo ser convencional com uso do Bilispot, que consiste em foco refletivo de luz halógena que atua de maneira localizada, com uma irradiância em torno 20 a 22 $\mathrm{uw} / \mathrm{cm}^{2} / \mathrm{nmo}$. Também é utilizado o biliberço, que atua com três lâmpadas fluorescentes azuis no centro e duas lâmpadas fluorescentes em cada uma das laterais (situadas sob o RN) que atingem uma extensa superfície corpórea, com uma irradiância de 18 a 27 $\mathrm{uw} / \mathrm{cm}^{2} / \mathrm{nmo}$. Cabe ao enfermeiro e toda equipe interdisciplinar conhecer as medidas de segurança em relação aos equipamentos de fototerapias utilizados no tratamento ao RN ictérico. A seguir, imagens de um Biliberço e de um Biliberço associado ao Bilispot.

\section{FOTOTERAPIA}

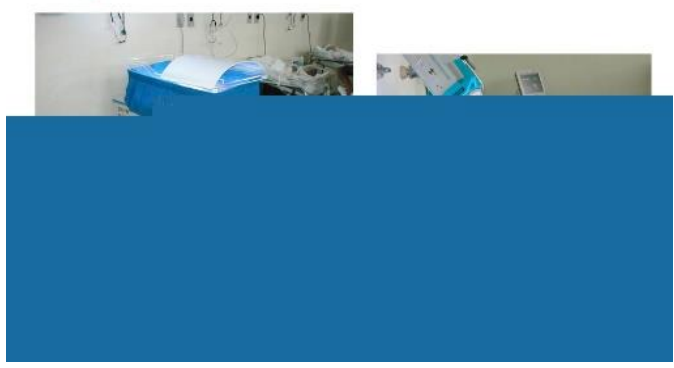

Fonte:

〈https://www.google.com/search?q=Biliber\% $\mathrm{C}_{3} \% \mathrm{~A} 7 \mathrm{o}+\mathrm{e}+$ fototerapi\&source $>$ Acesso (29 fev 2020) 
Em relação ao Quadro 2: "Estudos sobre ações assistenciais de enfermagem em relação à família do RNPT ictérico em âmbito domiciliar" BOTÊLHO et al (2012) objetivaram apreender as representações sociais de mães sobre o cuidar materno diante do filho prematuro. Participaram dessa pesquisa trinta mães de RNPT que estiveram em três serviços de estimulação precoce em Jequié-BA. O instrumento de coleta de dados foi o Teste de Associação Livre de Palavras, que solicitou às participantes que evocassem cinco palavras sobre o cuidar materno diante do filho prematuro e que atribuíssem ordem de importância para as palavras. Os dados foram processados pelo EVOC 2003, gerando um quadro de quatro casas. No quadrante superior esquerdo apareceram as palavras amor e cuidado; no superior direito, angústia, atenção, carinho, paciência; no inferior esquerdo, medo, prevenção; no inferior direito, alegria, dedicação, dependência, dificuldade, experiência, proteção, responsabilidade, superação. $\mathrm{O}$ amor e o cuidado aparecem como núcleo central das representações. $\mathrm{O}$ amor diz respeito ao papel de mãe a ser exercido. $\mathrm{O}$ cuidado pode representar o anseio de encontrar melhorias para seu filho. Os autores alegam que a espera de um filho saudável e nascido no tempo apropriado é completamente diferente da realidade de ter um filho que nasce antes do tempo e que necessita de cuidados especiais. Quando o bebê recebe alta hospitalar e vai para casa, quer dizer que a partir daquele momento o hospital não é mais responsável pelo seu cuidado, que passa a ser responsabilidade da família, especialmente da mãe. Nem todas as mães estão preparadas para o cuidado de um filho prematuro no próprio domicílio e tal fato pode se revelar assustador de certa forma. através de informações e orientações sobre o cuidado domiciliar dessa criança, preparando esses pais para uma nova realidade. Cabe à enfermagem prestadora de cuidados em domicílio, implementar uma assistência humanizada, com informações e orientações, utilizando linguagem acessível e acolhedora, em relação aos cuidados com o RNPT, e que ainda tenha de ser submetido ao tratamento de fototerapia. SASSA et al (2014) evidenciaram por meio de uma pesquisa convergente-assistencial, que a mãe e os demais familiares associaram o bebê nascido de muito baixo peso a uma condição de maior fragilidade e à probabilidade de doenças graves, mesmo após a alta hospitalar, o que constituiu motivo de ansiedade, apreensão e insegurança, que perduraram por longo período, suscitando dúvidas relacionadas aos cuidados a serem dispensados aos bebês nos domicílios. Nos primeiros dias em casa, as famílias se preocuparam em atender as necessidades da criança, especialmente com base no que vivenciaram e aprenderam durante a hospitalização, o que facilitou o cuidado, mas não as protegeu dos medos 
relacionados à fragilidade do filho. O preparo adequado da família para a alta, estimulando e reforçando a confiança dos pais em sua capacidade para cuidar da criança em casa é muito importante. Porém, é imprescindível que a criança esteja com o quadro clínico estável, que os pais apresentem condições físicas e emocionais adequadas, e que exista uma rede de serviço que possa ser acionada em casos de intercorrência e também para assessorar a família na implementação da assistência no domicílio. Ressalta-se que dúvidas em relação aos sinais e sintomas apresentados pelo bebê, suas características, riscos e fragilidades permearam o cuidado cotidiano no domicílio, o qual demanda das famílias tomadas de decisão contínuas, que, antes, eram guiadas pela rotina hospitalar. Muitos pais tinham a percepção de que, mesmo após a alta, ainda havia riscos para a saúde do bebê e que, apesar da estabilidade clínica alcançada, persistia a ameaça de intercorrências e agravos. Além disso, acredita-se que, embora por ocasião da alta a mãe já tenha vivenciado várias situações de cuidado do filho no ambiente hospitalar, a realidade no domicilio é muito diferente. Enquanto no hospital, ela conta com o apoio constate dos profissionais; no domicílio, muitas vezes, ela está sozinha, e, nesses casos, tendo ou não experiência de cuidado a outros filhos, a condição de prematuridade é associada à percepção de fragilidade do bebê, desencadeando a necessidade de um cuidado específico e diferenciado, que se torna possível ao estender a atenção profissional ao domicílio.

BRAUER (2017) em uma reportagem em Contagem, Minas Gerais, revela a primeira vez no âmbito do Sistema Único de Saúde (SUS) que um bebê foi desospitalizado para seguir tratamento de fototerapia no próprio domicílio. Onze profissionais estiveram envolvidos nesse procedimento, entre duas pediatras, dois enfermeiros, seis técnicos de enfermagem e um assistente social. Após quatro dias de tratamento domiciliar, a menina recebeu alta. Com a aquisição dos equipamentos de fototerapia, passou a ser possível desospitalizar até cinco crianças para tratamento de icterícia domiciliar, simultaneamente. A mãe foi capacitada para prestar cuidados específicos à filha, com supervisão da referida equipe de saúde. A internação para tratamento de icterícia no alojamento conjunto da maternidade local mostra que dos dezesseis leitos de enfermaria, de dois a quatro deles geralmente estão ocupados para tratamento de fototerapia. Nesses casos, o bebê precisa permanecer no hospital, ambiente no qual o risco de contrair infecções é maior. Há também a possibilidade da permanência no hospital provocar estresse e cansaço à criança e mãe. A diretora do Departamento de Atenção Domiciliar da Secretaria Municipal de Saúde 
(SMS), alega que sentimentos como estresse e depressão são frequentes no ambiente hospitalar e, que o atendimento em domicílio fortalece o vínculo familiar e o aleitamento materno.

ARAUJO et al (2014) analisaram dezessete publicações sobre o neonato em fototerapia, para que se fizesse a delimitação do foco principal de cada estudo. Foram obtidos os seguintes focos: percepções das mães sobre o neonato ao uso de fototerapia; acompanhamento da icterícia neonatal em recém-nascidos de termo e prematuros tardios; suporte materno domiciliar para o cuidado do recém-nascido prematuro até tratamentos alternativos para icterícia neonatal, cuidados com a pele do $\mathrm{RN}$ e apoio emocional às mães. De tais focos, emergiram três categorias temáticas sendo:I- Icterícia neonatal e seu tratamento através da fototerapia; 2- Conhecimento e percepção de mães sobre icterícia neonatal e 3-Assistência de Enfermagem ao RN com icterícia neonatal.

Com relação à primeira temática, evidencia-se o cuidado da pele do $\mathrm{RN}$ que apresenta na icterícia pele amarelo-alaranjada, com alteração na pigmentação do tecido cutâneo, devendo-se portanto usar na higienização do RN produtos como sabão neutro. Também, estar atento às lâmpadas da fototerapia, visando prover a irradiância adequada e o correto posicionamento para uma maior abrangência da área corporal da criança. Quanto a segunda temática, os sentimentos maternos são caracterizados por estados de afetividade, podendo ser positivos ou negativos, provenientes das percepções criadas. Em relação às percepções maternas, pode-se analisar que as mães possuem um temor ao colocar o neonato em uso de fototerapia. As mesmas acreditam que a proteção ocular, por deixar tudo escuro, pode doer ou até mesmo cegar, enquanto outras mães observam a luz com um sentimento de pavor. Como a pele do neonato esquenta, há um sentimento de apreensão, pois existe o temor de que o bebê esteja com dores ou que sua pele esteja sendo queimada. Os autores observaram o desconhecimento das mães sobre o tratamento fototerápico. Esse desconhecimento da terapêutica gera perturbações e nervosismo para mãe ao ver o seu filho ser submetido a um tratamento para elas desconhecido, onde a mesma não sabe seus riscos. Cabe à enfermagem realizar esclarecimentos sobre os cuidados fototerápicos, minimizando os medos e inseguranças dos genitores e familiares. Frente à terceira temática, nota-se uma incompreensão da família em relação ao tratamento, a patologia e uma carência de informações, revelando uma falha na comunicação entre a equipe de enfermagem e os pais, tendo como consequência a confusão de pensamentos destes. É 
importante enfatizar a adequada comunicação entre pais e profissionais. Os referidos autores apontam à necessidade de capacitação e educação dos enfermeiros para uma melhor elaboração dos diagnósticos envolvendo os RNPT e fototerapia.

BRASIL (2014b), pelo manual de AIDPI Neonatal relata as vantagens do leite materno como: Nutricionais (com nutrientes compatíveis para a fácil digestão do RN, sendo: caseína, lactoalbumina, lípides, lactose, sais minerais, diminuindo risco de alergia e problemas cardiovasculares, de obesidade, efeito positivo no desenvolvimento da inteligência entre outros); Imunológicos (com imunoglobulinas IGA, IGG, IGM, lactoferrina, lactobacilos e ação acidófila do leite com macrófagos, linfócitos, granulócitos, evitando infecções); Psicossociais (com estreitamento do vínculo afetivo mãe-filho); Econômicos (com nutrientes necessários à criança até os seis meses de idade). Também, evidenciam-se vantagens maternas como: proteção contra o câncer de mama, ajuda o útero a recuperar seu tamanho normal e aumenta as reservas de ferro, dentre outras). Contudo, evidencia que a icterícia no RN pode ocorrer pelo leite materno, devido a esse leite ter uma atividade de lipase elevada, que, uma vez ingerido pela criança, libera grande quantidade de ácidos graxos que interferem com a captação e/ou conjugação da bilirrubina, e a icterícia aparece mais tardiamente por volta do $10^{\circ}$ dia.

Nessa vertente, Dalcin (2016) ratifica que a icterícia do leite materno pode ser definida como a persistência da "icterícia fisiológica" além da primeira semana de vida. É distinguida da icterícia do aleitamento, relacionada a baixo aporte de leite, que ocorre nos primeiros sete dias de vida, resultando em perda excessiva de líquidos e peso. Deve-se descartar causas patológicas antes da icterícia ser diagnosticada como proveniente do leite materno, com exames como: nível de bilirrubina aumentado rapidamente nas $24 \mathrm{~h}$ (valores de bilirrubina total acima de $12 \mathrm{mg} / \mathrm{dl}$ antes de 24 a $36 \mathrm{~h}$ de vida; deficiência de G6PD ( glicose 6 fosfato desidrogenase), asfixia, sepse, acidose, albumina menor 3g/dl. O referido autor, médico pediatra, aconselha a não orientar a suspensão do leite materno rotineiramente. A suspensão de aleitamento materno só é aconselhada se os níveis totais de bilirrubina estiverem próximos aos níveis de indicação de exsanguíneotransfusão, conforme protocolo do Ministério da Saúde, de níveis de bilirrubina total, de acordo com a idade gestacional ao nascer e a idade em horas de vida. Como exemplo, segundo o referido protocolo, um RN maior ou igual a 38 e 6/7 semanas com 24 horas de vida, terá indicação para realizar a exsanguineotransfusão com nível de Bilirrubina Total (BT) em I8mg/dl. 
Por outro lado, caso esteja no $7^{\circ}$ dia de vida, para realizar a exsanguineotransfusão, o nível de BT deverá atingir $24 \mathrm{mg} / \mathrm{dl}$. A Enfermagem deverá estar ciente desse protocolo para atuar em um contexto interdisciplinar, atuando conjuntamente ao médico, orientando à família, e acompanhando os dados clínicos e laboratoriais da criança para a rápida intervenção quanto ao momento das indicações de fototerapia ou de exsanguineotransfusão, conforme a idade gestacional ao nascer e a idade em horas de vida da criança.

\section{CONSIDERAÇÕES FINAIS}

Por meio de revisão bibliográfica esse estudo objetivou analisar na literatura cientifica nacional ações assistenciais de enfermagem em domicilio, serviço Home Care, em relação ao RNPT que necessita de fototerapia no contexto familiar. Duas categorias foram elaboradas sendo: "Estudos sobre ações assistenciais de enfermagem em relação ao RNPT ictérico que necessita de fototerapia, em âmbito domiciliar" e "Estudos sobre ações assistenciais de enfermagem em relação à família do RNPT ictérico em âmbito domiciliar".

A pesquisa mostra a atuação do enfermeiro, inserido na equipe multidisciplinar do serviço

de Home Care, na implementação de cuidados ao RN ictérico em domicilio. Torna-se crucial diferenciar a icterícia fisiológica ou tardia da patológica, uma vez que a icterícia fisiológica surge após 48 horas de vida como autolimitada, sem significar necessariamente presença de doença, tendo como uma das causas principais a dificuldade na conjugação da BI em BD devido a imaturidade hepática e, consequente baixa produção da enzima glucoronil-transferase, uma das responsáveis por essa conjugação. O uso exclusivo de fototerapia, geralmente auxilia no tratamento da icterícia fisiológica. Contudo, a icterícia patológica ou precoce, surge antes das 24 horas de vida, tendo como causas principais: a doença hemolítica, infecções congênitas e sepse. Devido a imaturidade hepática do RNPT, as fases de captação e conjugação da bilirrubina indireta são comprometidas, aumentando a circulação da mesma no sangue, podendo levar à encefalopatia bilirrubínica ou Kernicterus, com possível comprometimento do sistema nervoso central. Nesse caso, a fototerapia é associada ao procedimento de exsanguineotransfusão, entre outras terapêuticas, sendo tal tratamento, geralmente, realizado em ambiente hospitalar.

A pesquisa demonstra a importância do atendimento Home Care, utilizando-se a fototerapia, quando indicada com acompanhamento médico, principalmente ao RNPT 
com icterícia fisiológica. O enfermeiro, inserido na equipe interdisciplinar (médicos, psicólogos entre outros) devem apresentar competências e habilidades para implementar ações assistenciais a partir do diagnóstico da icterícia, avaliando-se níveis de bilirrubina (direta e indireta) associando à idade gestacional ao nascer e a idade em horas de vida da criança. Durante o uso da fototerapia, deve-se atentar às lâmpadas da mesma, visando prover a irradiância adequada e o correto posicionamento para uma maior abrangência da área corporal da criança, que permanecerá apenas com o uso da fralda para melhor eficiência da fototerapia. Também, orientações aos familiares quanto a ação terapêutica dessas lâmpadas, ora fluorescentes, em caso do uso de Biliberço, ou halógenas (azuis) em caso do Bilispot, minimizando os níveis de bilirrubina circulante. A literatura salienta que muitos pais têm pavor dessas lâmpadas, com medo de superaquecimento e possíveis queimaduras no bebê, sem falar do uso necessário da proteção ocular da criança, considerado desconfortável à família, durante a utilização do equipamento pelo RN. Acrescido a esses medos, muitos genitores desconhecem as causas da icterícia, devido a carência de informações e falhas na comunicação da equipe. $O$ desconhecimento da terapêutica gera ansiedade à mãe ao ver seu filho ser submetido a um tratamento para ela desconhecido. Cabe à enfermagem utilizar linguagem acessível durante as orientações.

Deve-se estimular cuidados diretos ao filho, notado pelos genitores como um ser fragilizado e vulnerável às infecções, devido a prematuridade. Estimular o aleitamento materno, pelos seus atributos nutricionais, imunológicos e psicossociais, com um maior estreitamento do vínculo mãe-filho. A suspensão de aleitamento materno só é aconselhada se os níveis totais de bilirrubina estiverem próximos aos níveis de indicação de exsanguíneotransfusão e, após terem sido descartadas outras causas patológicas como deficiência de albumina entre outras.

Durante o levantamento de artigos sobre a referida temática, notou-se uma carência de publicações quanto a assistência de Enfermagem em Home Care implementada ao RN em geral e, em especial ao RNPT ictérico submetido à fototerapia, tanto em serviços públicos (SUS) como particulares (Planos de Saúde). Das 8I publicações levantadas entre as bases Scielo e Lilacs, apenas io foram selecionadas, devido a grande maioria serem voltadas ao Home Care à população idosa. Daí, a necessidade dessa pesquisa em abranger também publicações eletrônicas, incluindo dois sites educativos científicos, e uma reportagem de 
Minas Gerais, descrevendo o primeiro atendimento domiciliar pelo SUS, de RN ictérico submetido à fototerapia por uma equipe interdisciplinar.

Tornam-se necessárias mais publicações a respeito do atendimento de Enfermagem ao RNPT ictérico em Home Care, se possível, incluindo o uso do tratamento fototerápico, trazendo mais evidencias a respeito dos benefícios ao bebê e família quanto aos cuidados realizados no próprio domicilio, como: estreitar o vínculo familiar, minimizando medo e ansiedade dos pais; mostrar estatisticamente a diminuição de processos infecciosos por estar em ambiente extra hospitalar, com diminuição de custos; Dimensionar leitos hospitalares voltados mais ao atendimento de RN com icterícia patológica, necessitando de cuidados mais complexos.

Esse estudo procurou contribuir para uma maior conscientização da importância da assistência de enfermagem domiciliar, em serviços de Home Care, trazendo um novo olhar de atendimento humanizado e de qualidade.

\section{REFERÊNCIAS}

ARAUJO, IRB et al. Assistência de enfermagem ao recém-nascido com icterícia neonatal: uma revisão integrativa. Disponível em: 〈https://www.researchgate.net/publication/322606408> Acesso em (29 fev 2020)

BARDIN, L. Análise de Conteúdo. Lisboa: Edições 70, 2004.

BOTÊLHO, SM et al. O cuidar materno diante do filho prematuro: um estudo das representações sociais. Disponível em: < (http://www.scielo.br/scielo.php?script=sci_arttext\&pid=Soo806234201200040002I\&lng=pt $\& \mathrm{nrm}=$ iso\&tlng=pt $>$ Acesso em (29 fev 2020)

BRASIL. Ministério da Saúde. Secretaria de Atenção à Saúde. Departamento de Atenção Básica. Caderno de atenção domiciliar, p.59 / Ministério da Saúde, Secretaria de Atenção à Saúde, Departamento de Atenção Básica. - Brasília : Ministério da Saúde, 2013. Disponível em:http://bvsms.saude.gov.br/bvs/publicacoes/caderno_atencao_domiciliar_melhor_casa. pdf> Acesso em (29 fev 2020)

BRASIL (a). Ministério da Saúde. Secretaria de Atenção à Saúde. Departamento de Ações Programáticas Estratégicas. Atenção à saúde do recém-nascido: guia para os profissionais de saúde / Ministério da Saúde, Secretaria de Atenção à Saúde, Departamento de Ações Programáticas Estratégicas. - 2. ed. atual. - Brasília : Ministério da Saúde, 2014. Disponível em 〈http://bvsms.saude.gov.br/bvs/publicacoes/atencao_saude_recem_nascido_vi.pdf〉 Acesso em ( $29 \mathrm{fev} 2020$ )

BRASIL (b). Ministério da Saúde. Secretaria de Atenção à Saúde. Departamento de Ações Programáticas e Estratégicas. Manual AIDPI Neonatal: quadro de procedimentos, pi23. 5. ed. Brasília: Ministério da Saúde, 2014. Disponível: < 
http://bvsms.saude.gov.br/bvs/publicacoes/maual_aidpi_neonatal_quadro_procedimentos .pdf $>$ Acesso em (6 fev 2020)

BRAUER, C. Primeiro atendimento de fototerapia feito em casa. Disponível em: < http://www.contagem.mg.gov.br/?materia=656232> Acesso em ( 25 fev 2020)

CASTRO, E et al. Atendimento de Enfermagem domiciliar na icterícia neonatal, 2oIr. Disponível em< http://enfermeiras-ad.blogspot.com/20II/o5/ictericia-neonatal.html> Acesso em (26 fev 2020)

COFEN. Resolução no 0464 de 03 de novembro de 2014. Normatiza a atuação da equipe de enfermagem na atenção domiciliar. Disponível em < http://www.cofen.gov.br/resolucaocofen-no-04642014_27457.html> Acesso em (25 fev 2020)

DALCIN, T. Como identificar e manejar a icterícia do leite materno? Disponível em: < https://www.ufrgs.br/scielo/telessauders/perguntas/como-identificar-e-manejarictericia-do-leite-materno> Acesso em (29 fev 2020)

FERREIRA, EA et al. Um estudo bibliográfico sobre o apego mãe e filho: bases para a assistência de enfermagem pediátrica e neonatal. Rev. Latino-Am. Enfermagem, Ribeirão Preto, v. 6, n. 4, p. III-II6, out. I998. Disponível em:

〈http://www.scielo.br/scielo.php?script=sci_arttext\&pid=Soro411691998000400oI 4 \&lng=pt $\& \mathrm{nrm}=\mathrm{iso}>$. Acesso em (13 fev 2020)

GARCIA, RSF. A história do Home Care no Brasil. 2014. Disponível em: < https://www.webartigos.com/artigos/a-historia-do-home-care-no-brasil/1207II) Acesso em ( $25 \mathrm{fev} 2020$ ).

GERMANO, FT et al. Assistência de enfermagem ao recém-nascido em fototerapia: uma revisão de literatura. Disponível em:

〈http://www.scielo.cl/pdf/cienf/vi2nI/arto8.pdf>Acesso em (29 fev 2020)

GIL, AC. Como elaborar projetos de pesquisa. 4 ed. São Paulo:Atlas, 2002. Disponível em: 〈https://professores.faccat.br/moodle/pluginfile.php/r3410/mod_resource/content/I/com o_elaborar_projeto_de_pesquisa__antonio_carlos_gil.pdf> Acesso em (I2 fev 2020).

GUIMARÃES, EAA. Prevalência e fatores associados à prematuridade em Divinópolis, Minas Gerais, 2008-2011: análise do Sistema de Informações sobre Nascidos Vivos, 2017. Disponível em: < http://www.scielo.br/scielo.php?script=sci_arttext\&pid=S22379622201700o10oo9I> Acesso em (20 fev 2020)

LEONE, C et al. Assistência integrada ao Recém Nascido de Baixo Peso. São Paulo: Atheneu, 2012 .

MAlagutTI, W. Assistência Domiciliar: Atualidades da Assistência de Enfermagem. Rio de Janeiro: Rubio, 2012.

MUNHOZ, $\mathrm{BZ}$ et al. Investigação de icterícia. Disponível em: < http://docs.bvsalud.org/biblioref/2018/o3/881609/investigacao-de-ictericia.pdf> Acesso em ( 29 set 2020) 
OLIVEIRA, LL et al. Fatores maternos e neonatais relacionados à prematuridade. Rev. Esc.

Enferm.USP, v5o (3), 2016.Disponívelem:<http://www.scielo.br/scielo.php?pid=Soo8062342 or6000300382\&script =sci_arttext \&tlng=pt $>$ Acesso em (29 fev 2020).

PEDILAR. A desospitalização em pediatria: quando adotar a internação pediátrica domiciliar? Disponível em: < https://www.pedilar.com.br/internacao-pediatricadomiciliar/> Acesso em (6 nov 2019).

PRADO FILHO, HR (2019). O desempenho dos equipamentos de fototerapias para recém-nascidos. Disponível em: < https://qualidadeonline.wordpress.com/2019/o9/o4/odesempenho-dos-equipamentos-de-fototerapia-para-recem-nascido/> Acesso em (26 fev 2020)

QUINTAL, VS. Icterícia neonatal: incompatibilidade materno-fetal. 1994.Disponível em: $<$ https://slideplayer.com.br/slide/ro7478or/> Acesso em (29 fev 2020)

RODRIGUES FPM et al. Normas e Condutas em Neonatologia. 2 ed. São Paulo: Atheneu; 20II.

SARMENTO, GJV. Fisioterapia Respiratória no Paciente Crítico: Rotinas Clínicas. Barueri SP: Manole, 2005.

SASSÁ, AH. et al. Ações de Enfermagem na assistência domiciliar ao Recém-Nascido de muito baixo peso. Disponível em: <http://www.scielo.br/scielo.php?pid=Soro321002014000500016\&script $=$ sci_arttext\&tlng=pt $>$ Acesso em ( 15 fev 2020)

TAMEZ, RN; SILVA, MJP. Enfermagem na UTI Neonatal: Assistência ao RecémNascido de Alto Risco. $4^{\circ}$ edição. Rio de Janeiro: Editora: Guanabara Koogan, 2010.

TROIANO, C Entenda como funciona o Home Care. Disponível em < https://www.youtube.com/watch?v=30MmFzChD9Y>Acesso em (25 fev 2020) 